\title{
The Potential Role of Epigenetic Drugs in the Treatment of Anxiety Disorders
}

This article was published in the following Dove Press journal:

Neuropsychiatric Disease and Treatment

Jacob Peedicayil

Department of Pharmacology \& Clinical Pharmacology, Christian Medical College, Vellore, India
Correspondence: Jacob Peedicayil

Department of Pharmacology \& Clinical Pharmacology, Christian Medical College, Vellore, India

$\mathrm{Tel} / \mathrm{Fax}+9 \mathrm{I}-0416-2284237$

Email jpeedi@cmcvellore.ac.in
Abstract: There is increasing evidence that abnormalities in epigenetic mechanisms of gene expression contribute to the pathogenesis of anxiety disorders (ADs). This article discusses the role of epigenetic mechanisms of gene expression in the pathogenesis of ADs. It also discusses the data so far obtained from preclinical and clinical trials on the use of epigenetic drugs for treating ADs. Most drug trials investigating the use of epigenetic drugs for treating ADs have used histone deacetylase inhibitors (HDACi). HDACi are showing favorable results in both preclinical and clinical drug trials for treating ADs. However, at present the mode of action of HDACi in ADs is not clear. More work needs to be done to elucidate how epigenetic dysregulation contributes to the pathogenesis of ADs. More work also needs to be done on the mode of action of HDACi in alleviating the signs and symptoms of ADs.

Keywords: anxiety disorders, epigenetic, histone deacetylase, histone deacetylase inhibitor

\section{Introduction}

Anxiety disorders (ADs) are common disorders having a current global prevalence of $7.3 \%$, with a range of $4.8 \%$ to $10.9 \%$. ${ }^{1}$ The age of onset of these disorders is usually in the mid-twenties, and women are twice as likely than men to be diagnosed to have these disorders. ${ }^{2}$ In patients with ADs there is anxiety in situations where there is no external reason or cause for such distress, and the patient's daily functioning is affected. ${ }^{3}$ Such patients experience a diffuse, unpleasant, and vague feeling of apprehension, often accompanied by autonomic symptoms like headache, sweating, palpitations, tightness in the chest, mild abdominal discomfort, and restlessness. ${ }^{4}$ There is a high amount of co-morbidity between ADs and depressive disorders ${ }^{5}$ and drug addiction. ${ }^{6}$

ADs form a group of related but distinct psychiatric disorders including panic disorder (PD), agoraphobia, specific phobia, social anxiety disorder (SAD), and generalized anxiety disorder (GAD). ${ }^{4}$ PD involves acute intense attacks of anxiety with feelings of impending doom. Regarding PD, there can be many attacks in one day, or only a few attacks in a year. Agoraphobia refers to fear or anxiety about places from which escape may be difficult. Specific phobia involves an excessive fear of a specific object, circumstance, or situation. SAD (social phobia) refers to the fear of social situations which involve scrutiny or interaction with strangers. GAD involves anxiety about everything, for most days during at least a six-month period. ${ }^{4}$ The different subtypes of ADs often occur together in the same patient. ${ }^{5}$

\section{Pathogenesis of Anxiety Disorders}

Both psychological and biological factors are thought to contribute to the pathogenesis of ADs. ${ }^{4}$ Psychological factors involved in the pathogenesis of ADs comprise 
traumatic and stressful life events, especially during childhood. $^{7}$ There is consistent evidence that many types of psychosocial stress increase the synthesis and release of cortisol. ${ }^{4}$ Cortisol helps to mobilize and restore energy stores and contributes to changes like increased arousal, vigilance, focused attention, and memory formation. ${ }^{4}$ However, excessive and sustained cortisol secretion can lead to serious adverse effects like hypertension, dyslipidemia, insulin resistance, and cardiovascular disease. ${ }^{4}$ In addition to psychological factors, biological factors play a crucial role in the pathogenesis of ADs. For example, family and twin studies have shown that genetic factors are involved in the pathogenesis of ADs. ${ }^{7}$ Segregation analysis has shown that ADs are not Mendelian disorders, but complex traits involving multiple genes interacting with environmental factors resulting in the development of the disorders in affected individuals. ${ }^{7}$ However, linkage and candidate gene studies have produced inconclusive results, and genome-wide association studies (GWAS) have so far not reached genome-wide significance. ${ }^{8}$ Hence, at present, the results of genetic mapping studies are equivocal and inconclusive. ${ }^{8}$ The autonomic nervous system of some patients with ADs, especially those suffering from PD, shows raised sympathetic tone, slow adaptation to repeated stimuli, and excessive response to moderate stimuli. ${ }^{4}$ Abnormal functioning of three neurotransmitters, noradrenaline, serotonin, and $\gamma$-aminobutyric acid (GABA) has been implicated in the pathogenesis of ADs. ${ }^{4}$ Neuroimaging studies have commonly implicated the amygdala, insula, and prefrontal cortex (PFC) in the pathophysiology of ADs. ${ }^{9}$

\section{Current Pharmacotherapy of Anxiety Disorders}

Many of the currently used drugs for ADs modify the functioning of noradrenaline, serotonin, and GABA by enhancing their actions. Currently used antianxiety (anxiolytic) drugs include selective serotonin reuptake inhibitors (SSRIs), serotonin-noradrenaline reuptake inhibitors (SNRIs), benzodiazepines, buspirone, and ß-adrenergic receptor blockers. ${ }^{10}$ The histamine-1 receptor blocker hydroxyzine which causes short-term sedation, is used in treating patients in whom other anxiolytic drugs are not recommended. ${ }^{10}$ The anticonvulsant drug pregabulin may be useful in the treatment of ADs, as in some patients with GAD, SAD, and PD., ${ }^{411}$ The monoamine oxidase inhibitor moclobemide may be helpful in treating severe cases of SAD. ${ }^{4,11}$

The drug of choice for treating ADs depends on the subtype of the disorder and the clinical need for acute anxiolytic effects. ${ }^{11}$ Among the drugs, only the benzodiazepines and the $\beta$-adrenergic receptor blockers are effective acutely. For the treatment of chronic anxiety SSRIs and SNRIs are used. For situational anxiety, the Badrenergic receptor blockers are used. For example, propranolol, in conjunction with psychological intervention, has been shown to decrease anxiety in subjects who develop situational anxiety due to spiders. ${ }^{12}$ For immediate effects, the benzodiazepines are used. ${ }^{11}$ In conjunction with pharmacotherapy, psychotherapy is essential for the effective control of symptoms of patients with ADs. ${ }^{6}$

\section{Outline of Epigenetics}

Epigenetics, which literally means above, or in addition to, genetics, is presently an active area of research in both biology and medicine. It refers to heritable changes in gene expression not involving changes in DNA sequence. It involves molecular mechanisms like DNA methylation, DNA hydoxymethylation, histone modifications, and noncoding RNA (ncRNA)-mediated regulation of gene expression. ${ }^{13}$ Regarding ncRNAs, they can be considered to be a part of epigenetics, when epigenetics is considered in a broad sense. ${ }^{13}$ For example, epigenetic mechanisms of gene expression like DNA methylation can regulate ncRNA expression. ${ }^{14}$ Conversely, ncRNAs can regulate epigenetic mechanisms of gene expression. For example, ncRNAs can regulate the expression of genes encoding proteins like DNA methyltransferases (DNMTs) that are involved in the epigenetic regulation of gene expression. ${ }^{14}$ ncRNAs can be classified based on size into long ncRNAs (lncRNAs) which are more than 200 base pairs long and short ncRNAs which are less than 200 base pairs long. ${ }^{13}$ The most extensively studied short ncRNAs are microRNAs (miRNAs). ${ }^{13}$

Epigenetic mechanisms of gene expression are known to interact with each other. Unlike the DNA sequence, epigenetic mechanisms of gene expression are relatively easily modified by the environment. ${ }^{15}$ Epigenetic mechanisms of gene expression are known to vary between cells and tissues and also show temporal variation. ${ }^{16,17}$ There is increasing evidence that abnormalities in epigenetic mechanisms of gene expression contribute to the pathogenesis of disease, especially common disease. Indeed, epigenetics has been referred to as the epicenter of modern 
medicine. ${ }^{18}$ There is also increasing evidence that epigenetic mechanisms of gene expression are dysregulated in virtually every type of psychiatric disorder and that dysregulated epigenetic mechanisms contribute to their pathogenesis. ${ }^{16,17,19}$

\section{Role of Epigenetics in the Pathogenesis of Anxiety Disorders Scope of Epigenetics in Anxiety Disorders}

Several lines of evidence suggest that abnormalities in epigenetic mechanisms of gene expression contribute to the pathogenesis of ADs: 1. As alluded to above, no genetic mutation or polymorphism underlying these disorders has been conclusively identified. 2. The concordance rate of identical twins for ADs is only 30 to $40 \%$, supporting the idea that there are environmental factors involved in their pathogenesis. ${ }^{20,21} 3$. Environmental factors, especially psychosocial stress, are known to influence the pathogenesis of ADs. ${ }^{22} 4$. There are gender differences in the epidemiology of ADs: The lifetime prevalence of ADs in women is $30.5 \%$ whereas in men it is $19.2 \%{ }^{4} 5$. As given below, there is experimental evidence that epigenetic mechanisms of gene expression are dysregulated in patients with ADs.
To date, no study has investigated epigenetic changes in the post-mortem brain of patients with ADs. The reason for this is the practical difficulty of obtaining suitable postmortem brain tissues from patients diagnosed to have ADs. However, studies have been conducted on peripheral cells and tissues obtained from patients with ADs as proxies for brain tissues.

\section{Roles of DNA Methylation and Histone Modifications in Anxiety Disorders}

Changes in DNA methylation and histone modifications in animal models of ADs are listed in Table 1 and in peripheral cells in patients with ADs in Table 2. It is interesting that in two studies ${ }^{24,25}$ hypermethylation of the GAD1 gene, which encodes the enzyme glutamic acid decarboxylase1, the enzyme that catalyzes the decarboxylation of glutamic acid to GABA, was found. Hypermethylation of DNA correlates with inhibition of gene expression. ${ }^{13}$ Hence hypermethylation of GAD1 would lead to reduced expression of GAD1, and hence reduced formation of GABA, the major inhibitory neurotransmitter in the brain. In this context, it is known that patients with PD have been found to have lower brain concentrations of

Table I Epigenetic Changes in Animal Models of Anxiety Disorders

\begin{tabular}{|l|l|l|}
\hline Tissue & Epigenetic Change & References \\
\hline Rat developing hippocampus, amygdala & DNA methylation changes & {$[23]$} \\
Rat basolateral amygdala & Hypermethylation in GADI gene & {$[24]$} \\
Mouse basolateral amygdal & Hypermethylation of GADI gene & {$[25]$} \\
Rat hippocampus & Hypermethylation of Nr3cl gene & {$[26]$} \\
Rat amygdala & Hypermethylation of developing brain & {$[27]$} \\
Rat amygdala & BDNF gene hypermethylation & {$[28]$} \\
Rat amygdala & Aberrant HDAC2-mediated histone modifications & {$[29]$} \\
Rat hippocampus & Differential histone acetylation and methylation & {$[30]$} \\
Rat hippocampus & H3 histone acetylation; modulation of methyl-CpG-binding & {$[3 /]$} \\
Mouse cerebral cortex & Down-regulation of HDAC2 associated with BDNF gene & {$[32]$} \\
Rat hippocampus & Reduces H3KI4 acetylation due to prenatal dexamethasone & {$[33]$} \\
Rat hippocampus & Decreases H3K9 and H4KI2 acetylation due to social isolation & {$[34]$} \\
Rat PFC & Reduces H3/H4 acetylation after extinction training & {$[35]$} \\
Rat nucleus accumbens & Inhibition of G9a/GLP HMT & {$[36]$} \\
Mouse medulla oblongata & Histone modifications of genes affecting neurodevelopment and emotionality & {$[37]$} \\
Mouse hippocampus and amygdala & Dysregulation of miR-I32/2I2 & {$[38]$} \\
Rat amygdala & Over-expression of miR-I0la and its target Ezh2 & {$[39]$} \\
Rat PFC and hippocampus & Changes in miRNA-I35a and miRNA-I6 \\
Rat amygdala and PFC & Microbial regulation of miRNA expression \\
Mouse PFC & IncRNA Gomafu associated with anxiety & {$[40]$} \\
\hline
\end{tabular}

Abbreviations: BDNF, brain-derived neurotrophic factor; GADI, glutamic acid decarboxylasel; $\mathrm{HDACi}$, histone deacetylase inhibitor; HMT, histone methyltransferase; IncRNA, long non-coding RNA; miRNA, microRNA; PFC, prefrontal cortex. 
Table 2 Epigenetic Changes in Human Peripheral Cells in Anxiety Disorders

\begin{tabular}{|l|l|l|}
\hline Tissue & Epigenetic Change & References \\
\hline Whole blood & I83 differentially methylated loci & {$[46]$} \\
Blood cells & GADI gene hypomethylation & {$[47]$} \\
Buccal cells & Hypomethylation of SERT gene & {$[48]$} \\
Whole blood & MAOA gene hypomethylation & {$[49]$} \\
Whole blood & Several CpG sites hypomethylated & {$[50]$} \\
Saliva cells & Hypomethylation of MAOA gene & {$[5 I]$} \\
Whole blood & Hypomethylation of oxytocin receptor gene & {$[52]$} \\
Saliva & Hypermethylation in AA genotype of OXTR rs53576 & {$[53]$} \\
PBMCs & Global DNA hypermethylation & {$[54]$} \\
Leukocytes & Glucocorticod receptor gene hypermethylation & {$[55]$} \\
Whole blood & Hypermethylation of FOXP3 promoter & {$[56]$} \\
Whole blood & Hypermethylation of HECA gene in females & {$[57]$} \\
Saliva cells & Neurodevelopmental pathway gene hypermethylation & {$[58]$} \\
Whole blood & Hypermethylation of STK32B promoter & {$[59]$} \\
Peripheral venous blood & Hypermethylation of BDNF gene & {$[60]$} \\
Peripheral blood & Hypermethylation of NR3CI gene & {$[6 I]$} \\
Saliva & Hypermethylation of NR3CI gene & {$[62]$} \\
Peripheral blood & Hypermethylation of FKBP5 gene & {$[63]$} \\
Saliva & Hypermethylation of BDNF and oxytocin receptor genes & {$[64]$} \\
Whole blood & hsa-miR-579-3P upregulates fear and anxiety & {$[65]$} \\
PBMCs & Increases miR-663 expression & {$[66]$} \\
Sperm & Reduces levels of miRNAs 449 and 34 & {$[67]$} \\
Peripheral blood & Moderating effect of miRNAs on workplace bullying & {$[68]$} \\
\hline
\end{tabular}

Abbreviations: GADI, glutamic acid decarboxylasel; miRNA, microRNA; PBMCs, peripheral blood mononuclear cells.

GABA than healthy controls. ${ }^{43,44}$ However, the data on GABA concentrations in plasma and cerebrospinal fluid of patients with anxiety is contradictory, possibly due to differences between studies in study design and methodology, tissues where sampling was done, and patient populations. Supporting a direct role for GABA in ADs is the recent finding of $\mathrm{He}$ et $\mathrm{al}^{45}$ that repeated oral administration of GABA to emotionally stressed rats was found to reduce anxiety. These authors subjected the rats to stress using the open field and elevated plus maze models.

Stressful life events, especially those during childhood, are known to increase the risk for adult-onset ADs. ${ }^{69}$ Stress is known to activate many neuronal circuits, like those in the hippocampus, ${ }^{70}$ and the hypothalamicpituitary-adrenal (HPA) axis. Genes encoding proteins associated with the HPA axis like the glucocorticoid receptor (GR or NR3C1), corticotropin releasing factor (CRF), FK506 binding protein 5 (FKBP5; a co-chaperone of the glucocorticoid receptor), proopiomelanocortin (POMC), and vasopressin have been found to show abnormalities in DNA methylation by previous studies. ${ }^{69}$ These studies suggest that excessive stress due to dysregulation of the HPA axis caused by changes in DNA methylation of such genes can upregulate the HPA axis and increase anxiety. ${ }^{69}$ A consistent epigenetic change appears to be hypermethylation of the $\mathrm{Nr} 3 \mathrm{Cl}$ gene, the gene encoding the GR. Such findings have been seen in animal models of $\mathrm{ADs},{ }^{26}$ and in peripheral tissues of patients with ADs. ${ }^{61,62}$ Indeed, there is converging evidence that in individuals who experience stress during early life hypermethylation of the $\mathrm{Nr} 3 \mathrm{Cl}$ gene could contribute to the development of stress during adulthood. $^{71}$

The GR is also known to interact with histone deacetylase 6 (HDAC6) in the brain. Lee and co-workers, ${ }^{72}$ showed that acute stress, via the GR, increases glutamatergic signaling in the PFC of rats. The authors found that inhibition or knockdown of HDAC6 prevents the enhancement of glutamatergic signaling by acute stress. The same treatment of the GR chaperone protein HSP90, a substrate of HDAC6, produced similar results. These results suggested to the authors that HDAC6 is a key enzyme regulating the synaptic effects of acute stress in the PFC. Espallergues et $\mathrm{al}^{73}$ showed that selective knockout of HDAC6 in the dorsal raphe neurons in mice reduces the anxiogenic effects of glucocorticoids in mice. These authors found that in mice exposed to chronic social 
defeat, HDAC6 depletion in serotonergic neurons prevents social avoidance. HDAC6 depletion was associated with decreased interaction between HSP90 and the GR.

FKBP5 is a chaperone protein that negatively regulates GR sensitivity by reducing binding affinity and restricting nuclear translocation. ${ }^{69}$ Roberts et $\mathrm{al}^{63}$ found that the FKBP5 gene in peripheral venous blood is hypermethylated in patients with agarophobia with or without PD and that this is corrected by psychotherapy. These findings support the previous data of the same group $^{74}$ that children with ADs had hypermethylation in the FKBP5 gene and that this was corrected by psychotherapy.

Brain-derived neurotrophic factor (BDNF) is a member of a family of neurotrophins which also includes nerve growth factor. BDNF is a key regulator of neuronal differentiation, structure, and function. ${ }^{75}$ Moreover, there is evidence that BDNF modulates neuronal activity to impact complex human phenotypes like memory, anxiety, and depression. ${ }^{75}$ BDNF levels appear to be reduced in patients with ADs. ${ }^{76}$ However, this is not consistent across all the different subtypes of ADs. ${ }^{76}$ The gene encoding BDNF has been found to be epigenetically modified, with reports of hypermethylation in the rat amygdala, ${ }^{28}$ and peripheral venous blood, ${ }^{60}$ and saliva $^{64}$ of patients with ADs. Since hypermethylation is associated with reduced gene expression, this would lead to reduced levels of BDNF. The oxytocin neuropeptide system plays a role in social behavior and cognition. ${ }^{69}$ In this regard, the gene encoding the oxytocin receptor has shown changes in DNA methylation in patients with ADs. ${ }^{52,53,64}$

\section{Role of Non-Coding RNAs in Anxiety Disorders}

ncRNAs play a major role in neurogenesis and the regulation of normal neuronal function in the brain. ${ }^{77}$ For example, they regulate neuronal plasticity, learning and memory. ${ }^{78}$ There is also increasing evidence that ncRNAs, especially miRNAs, are involved in the pathogenesis of neuropsychiatric disorders including ADs. ${ }^{78}$ For example, experimental up- or down-regulation of candidate miRNAs associated with neurocircuits associated with anxiety can modulate anxietyrelated behavior in animal models of ADs. ${ }^{77}$

Studies on animal models of ADs suggest that specific miRNAs may play various roles in the development and progression of anxiety in a brain region-specific manner. ${ }^{78}$ Transposable elements (TEs) are mobile genetic elements (pieces of DNA capable of moving to new locations). ${ }^{79}$ They make up to two-thirds of the human genome. ${ }^{80}$ There is growing evidence of a close association between TEs and ncRNAs, and many small ncRNAs originate from TEs. ${ }^{79}$ TEs have been associated with disease pathology in patients with ADs. For example, stress can interact with the epigenome to regulate the expression of TEs in a region-specific manner to alter stress responsiveness, anxiety, and brain plasticity. ${ }^{81}$ Compared to changes in DNA methylation and histone modifications relatively few studies to date have investigated the role of ncRNAs in the pathogenesis of ADs (Tables 1 and 2).

\section{Trials of Epigenetic Drugs in Anxiety Disorders}

Table 3 lists preclinical drug trials that have evaluated epigenetic drugs for treating ADs. As shown, most of the trials have evaluated the use of HDAC inhibitors (HDACi) in

Table 3 Preclinical Trials of Epigenetic Drugs in Anxiety Disorders

\begin{tabular}{|l|l|l|l|l|}
\hline Drug & Class & $\begin{array}{l}\text { HDAC Class } \\
\text { Target of Drugs }\end{array}$ & Effect & References \\
\hline MS-275 & HDACi & I, III & Reduces anxiety in SI mice & {$[82]$} \\
TSA & HDACi & I, II & Has anxiolytic effects in rats & {$[83]$} \\
TSA & HDACi & I, II & Reduces anxiety-like behavior in rats & {$[84]$} \\
TSA, SAHA & HDACi & I, II,IV & Reduces anxiety-like behavior in Fischer rats & {$[85]$} \\
SAHA & HDACi & I, II,IV & Reduces stress-related behavior in rats & {$[86]$} \\
MS-275 & HDACi & I,III & Rescues enhanced innate anxiety in mice & {$[87]$} \\
TSA & HDACi & I,II & Reverses anxiety due to maternal binge drinking & {$[88]$} \\
SB,VA & HDACi & I,Ila & Reduces anxiety in mice & {$[89]$} \\
SAHA & HDACi & I,II, IV & Reduces corticosterone-induced stress in mice & {$[90]$} \\
Lactate & Natural drug & - & Promotes resilience to stress in C57BL/6 mice & {$[9 I]$} \\
\hline
\end{tabular}

Abbreviations: HDACi, histone deacetylase inhibitor; SAHA, suberoylanilide hydroxamic acid; SB, sodium butyrate; TSA, trichostatin A; VA, valproic acid. 
preclinical studies of the use of epigenetic drugs for treating ADs. All the preclinical drugs trials that evaluated the use of HDACi listed in Table 3 found that these drugs alleviate stress or anxiety. The HDACi that were evaluated (MS-275, trichostatin A (TSA), vorinostat, sodium butyrate, and valproic acid) belong to different classes of HDACi. However, it is to be noted that most of them inhibit HDACs I and/or II, both of which are class I HDACs. ${ }^{92}$ One study ${ }^{91}$ evaluated the use of the naturally occurring compound lactate which was found to promote resilience to stress in mice by modulating the activity of HDACs.

Table 4 lists the clinical trials of epigenetic drugs in the treatment of anxiety. As listed, all the clinical trials made use of valproate, which is known to functions as a HDACi. Five of the 6 trials tested the anxiolytic effect of valproate on patients with ADs, and all found valproate to give beneficial effects. ${ }^{93-97}$ One trial ${ }^{98}$ was conducted to determine whether valproate reduces anxiety in healthy subjects and it found that valproate reduces anxiety in such subjects. It must be noted that valproate in addition to acting as a HDACi, also inhibits nerve conduction, which could also contribute to its antianxiety effects.

miRNA-directed therapy is another option in the treatment of ADs. ${ }^{99}$ miRNAs in patients with ADs can be targeted to lead to an upregulation of the targeted miRNA. Another possible therapy involves the inhibition of miRNAs in order to reduce their effects in target areas. Antagomirs and antisense oligonucleotides are being investigated for inhibiting miRNAs in preclinical drug trials. ${ }^{99}$ However, miRNA-directed therapy in psychiatric disorders including ADs is in its early stages, and much more research needs to be done in order to take this field forward. ${ }^{99}$

Table 4 Clinical Trials of Epigenetic Drugs in Anxiety Disorders

\begin{tabular}{|l|l|l|l|l|}
\hline Drug & Class & $\begin{array}{l}\text { HDAC } \\
\text { Class } \\
\text { Target of } \\
\text { Drugs }\end{array}$ & Finding & References \\
& & & \\
\hline Valproate & HDACi & I, lla & Decreases panic disorder & {$[93]$} \\
Valproate & HDACi & I, lla & Ameliorates panic disorder & {$[94]$} \\
Valproate & HDACi & I, lla & Decreases panic disorder & {$[95]$} \\
Valproate & HDACi & I, lla & Decreases social anxiety & {$[96]$} \\
Valproate & HDACi & I, lla & Reduces anxiety & {$[97]$} \\
Valproate & HDACi & I,lla & Decreases anxiety in & {$[98]$} \\
& & & healthy subjects & \\
\hline
\end{tabular}

Abbreviation: $\mathrm{HDACi}$, histone deacetylase inhibitor.

\section{Implications of Trials of Epigenetic Drugs in Anxiety Disorders}

There are several classes of drugs that are effective for the treatment of ADs. However, there are problems with the currently available drugs. For example, about one third of patients with ADs do not adequately respond to the current drugs. $^{2}$ A related problem is treatment- resistant ADs. ${ }^{100}$ Another problem is adverse effects that include habituation, dependence, and abuse. ${ }^{10}$ In this light, new drugs could be useful in the treatment of patients with ADs. One potential class of new drugs for treating ADs is epigenetic drugs. As shown in Tables 3 and 4, preclinical and clinical drug trials using HDACi for the treatment of ADs are showing favorable results.

HDACs are a group of enzymes that belong to two families and four classes. ${ }^{101}$ The two families are the HDAC family and the Sir2 regulator family. In humans HDACs are divided into four classes based on sequence similarities. The class I enzymes are HDAC1, HDAC2, HDAC3, and HDAC8. The class II enzymes are HDAC4, HDAC5, HDAC6, HDAC7, HDAC9, and HDAC10. The class III enzymes have sequence similarity to the yeast Sir2 protein and are SIRT1, SIRT2, SIRT3, SIRT4, SIRT5, SIRT6, and SIRT7. Class IV HDACs has one enzyme, HDAC11.

When compared to histone acetyltransferases (HATs), the quest for specific histone substrates for HDACs has proved to be arduous. The problems encountered include very low measurable HDAC activity when HDACs are purified to homogeneity, and functional redundancy of many HDACs. ${ }^{101}$ HDACs also have non-histone substrates in addition to histones. Using high-resolution mass spectrometry, it was demonstrated that there are more than 3600 acetylation sites on 1750 proteins. The acetylation sites are present on nuclear, cytoplasmic, and mitochondrial proteins involved in many different cellular processes. ${ }^{102}$ The broad spectrum HDACi, SAHA and MS-275, were found to up-regulate about $10 \%$ of all the sites by at least a factor of 2 , indicating that many of these acetylation reactions are regulated by classical HDACs. Computational models suggest that many more acetylation sites occur. These findings suggest that acetylation due to HDACs is common in histone and non-histone proteins.

Clinically useful HDACi are classified according to their chemical structure ${ }^{92}$ into hydroxamic acids (vorinostat or SAHA, panobinostat, belinostat, TSA, quisinostat, rocilinostat, and abexinostat), short chain fatty acids 
(butyrate and valproic acid), cyclic peptides (romidepsin), and benzamides (mocetinostat or MGCD0103 and entinostat or MS-275). Most currently available HDACi inhibit classes I, II, and IV of the HDACs, but not SIRT enzymes. HDACi, like HDACs, affect several targets in addition to HDACs and have mechanisms of action other than inhibition of HDAC. Many targets of HDACi are involved in anti-tumor pathways. HDACi cause accumulation of acetylated forms of histone and non-histone proteins that regulate gene expression, cell proliferation, and cell death. ${ }^{103}$ Although HDACi can up-regulate global histone acetylation levels, they do not always cause histone hyperacetylation, particularly at regions near gene promoters. ${ }^{104}$ These drugs up-regulate or down-regulate an equal number of genes. Hence, at present, the possible mechanism of action of HDACi in the treatment of the ADs is unclear. However, it has been shown that HDACi in addition to causing histone acetylation, also cause DNA demethylation, possibly due to increased levels of the demethylating enzyme ten-eleven translocation methylcytosine dioxygenase 1 (TET1). ${ }^{105,106}$ Since several genes have been shown to be hypermethylated in animal models of ADs (Table 1) and in human peripheral cells in patients with ADs (Table 2), DNA demethylation of such genes by HDACi may contribute to the mechanism of action of HDACi in ADs.

As mentioned in the introduction, co-morbidity exists between ADs and depressive disorders. Since HDACi are giving favorable results in preclinical and clinical trials of depressive disorders, ${ }^{107}$ these drugs could be useful for treating patients with ADs who also have depressive symptoms. Since HDACi are known to have cognitionenhancing effects, this property of these drugs may also make them suitable for treating patients with ADs some of whom can experience cognitive deficits. ${ }^{108}$

\section{Conclusions}

Several lines of evidence suggest that disrupted epigenetic mechanisms of gene expression contribute to the pathogenesis of ADs. However, the study of the role of abnormal epigenetic mechanisms of gene expression in ADs is in its early stages, and more work needs to be done to clarify issues in this area. Preclinical and clinical drug trials suggest that HDACi give favorable results in the treatment of ADs. However, at present the mode of action of HDACi in ADs is not clear. More work needs to be done on elucidating the mode of action of HDACi in alleviating the signs and symptoms of ADs.

\section{Disclosure}

The author alone is responsible for the content and writing of this paper and he reports no conflicts of interest.

\section{References}

1. Stein DJ, Scott KM, de Jonge P, Kessler RC. Epidemiology of anxiety disorders: from surveys to nosology and back. Dialogues Clin Neurosci. 2017;19:127-136.

2. Maron E, Nutt D. Biological predictors of pharmacological therapy in anxiety disorders. Dialogues Clin Neurosci. 2015;17:305-317.

3. Feldman RS. Understanding Psychology. New York: McGraw-Hill; 2011.

4. Sadock BJ, Sadock VA, Ruiz P. Kaplan \& Sadock's Synopsis of Psychiatry. New York: Wolters-Kluwer; 2015.

5. Thibaut F. Anxiety disorders: a review of current literature. Dialogues Clin Neurosci. 2017;19:87-88.

6. Lüthi A, Lüscher C. Pathological circuit function underlying addiction and anxiety disorders. Nat Neurosci. 2014;17:1635-1643. doi:10.1038/nn.3849

7. Schiele MA, Domschke K. Epigenetics at the crossroads between genes, environment and resilience in anxiety disorders. Genes Brain Behav. 2018;17:1-15. doi:10.1111/gbb.2018.17.issue-3

8. Shimada-Sugimoto M, Otowa T, Hettema JM. Genetics of anxiety disorders: genetic epidemiological and molecular studies in humans. Psychiatry Clin Neurosci. 2015;69:388-401. doi:10.1111/ pcn.2015.69.issue-7

9. Taylor JM, Whalen PJ. Neuroimaging and anxiety: the neural substrates of pathological and non-pathological anxiety. Curr Psychiatry Rep. 2015;17:49. doi:10.1007/s11920-015-0586-9

10. O'Donnell JM, Bies RR, Shelton RC. Drug therapy of depression and anxiety disorders. In: Brunton LL, Hilal-Dandan R, Knollmann BC, editors. The Pharmacological Basis of Therapeutics. New York: McGraw-Hill; 2018:267-277.

11. Bandelow B, Michaelis S, Wedekind D. Treatment of anxiety disorders. Dialogues Clin Neurosci. 2017;19:93-106.

12. Soeter M, Kindt M. An abrupt transformation of phobic behavior after a post-retrieval amnesic agent. Biol Psychiatry. 2015;78:880-886. doi:10.1016/j.biopsych.2015.04.006

13. Allis CD, Caparros M-L, Jenuwein T, Lachner M, Reinberg D. Overview and concepts. In: Allis CD, Caparros M-L, Jenuwein T, Reinberg D, Lachner M, editors. Epigenetics. Cold Spring Harbor, NY: Cold Spring Harbor Laboratory Press; 2015:47-115.

14. Chhabra R. The epigenetics of noncoding RNA. In: Tollefsbol TO, editor. Handbook of Epigenetics: The New Molecular and Medical Genetics. Cambridge, MA: Elsevier; 2017:47-59.

15. Feil R, Fraga MF. Epigenetics and the environment: emerging patterns and implications. Nat Rev Genet. 2012;13:97-109. doi: $10.1038 / \mathrm{nrg} 3142$

16. Peedicayil J, Grayson DR. An epigenetic basis for an omnigenic model of psychiatric disorders. J Theor Biol. 2018;443:52-55. doi:10.1016/j.jtbi.2018.01.027

17. Peedicayil J, Grayson DR. Some implications of an epigenetic-based omnigenic model of psychiatric disorders. J Theor Biol. 2018;452:81-84. doi:10.1016/j.jtbi.2018.05.014

18. Feinberg AP. Epigenetics at the epicenter of modern medicine. JAMA. 2008;299:1345-1350. doi:10.1001/jama.299.11.1345

19. Lee R, Avramopoulos D. Introduction to epigenetics in psychiatry. In: Peedicayil J, Grayson DR, Avramopoulos D, editors. Epigenetics in Psychiatry. Waltham, MA, USA: Elsevier; 2014:3-25.

20. Marks IM. Genetics of fear and anxiety disorders. $\mathrm{Br}$ J Psychiatry. 1986;149:406-418. doi:10.1192/bjp.149.4.406

21. Hettema JM, Neale MC, Kendler KS. A review and meta-analysis of the genetic epidemiology of anxiety disorders. Am J Psychiatry. 2001;158:1568-1578. doi:10.1176/appi.ajp.158.10.1568 
22. Bartlett AA, Singh R, Hunter RG. Anxiety and epigenetics. $A d v$ Exp Biol Med. 2017;978:145-166.

23. Simmons RK, Howard JL, Simpson DN, Akil H, Clinton SM. DNA methylation in the developing hippocampus and amygdala of anxiety-prone versus risk- taking rats. Dev Neurosci. 2012;34:58-67. doi:10.1159/000336641

24. Zhou R, Chen F, Chang F, Bai Y, Chen L. Persistent overexpression of DNA methyltransferase 1 attenuating GABAergic inhibition in basolateral amygdala accounts for anxiety in rat offspring exposed perinatally to low- dose bisphenol A. J Psychiatr Res. 2013;47:1535-1544. doi:10.1016/j.jpsychires.2013.05.013

25. Zhu C, Liang M, Li Y, Feng X, Hong J, Zhou R. Involvement of epigenetic modifications of GABAergic interneurons in basolateral amygdala in anxiety-like phenotype of prenatally stressed mice. Int J Neuropsychopharmacol. 2018;21:570-581. doi:10.1093/ijnp/ pyy006

26. Kosten TA, Huang W, Nielsen DA. Sex and litter effects on anxiety and DNA methylation levels of stress and neurotrophin genes in adolescent rats. Dev Psychobiol. 2014;56:392-406. doi:10.1002/dev.v56.3

27. Mccoy CR, Glover ME, Flynn LT, et al. Altered DNA methylation in the developing brains of rats genetically prone to high versus low anxiety. J Neurosci. 2019;39:3144-3158. doi:10.1523/ JNEUROSCI.1157-15.2019

28. Sagarkar S, Bhamburkar T, Shelkar G, Choudhary A, Kokare DM, Sakharkar AJ. Minimal traumatic brain injury causes persistent changes in DNA methylation at BDNF gene promoters in rat amygdala: a possible role in anxiety-like behaviors. Neurobiol Dis. 2017;106:101-109. doi:10.1016/j.nbd.2017.06.016

29. Moonat S, Sakharkar AJ, Zhang H, Tang L, Pandey SC. Aberrant HDAC2-mediated histone modifications and synaptic plasticity in the amygdala predisposes to anxiety and alcoholism. Biol Psychiatry. 2013;73:763-773. doi:10.1016/j.biopsych.2013.01.012

30. Suri D, Bhattacharya A, Vaidya VA. Early stress evokes temporally distinct consequences on the hippocampal transcriptome, anxiety and cognitive behaviour. Int J Neuropsychopharmacol. 2014;17:289-301. doi:10.1017/S1461145713001004

31. Patki G, Solanki N, Atrooz F, et al. Novel mechanistic insights into treadmill exercise based rescue of social defeat-induced anxiety-like behavior and memory impairment in rats. Physiol Behav. 2014;130:135-144. doi:10.1016/j.physbeh.2014.04.011

32. Kumari A, Singh P, Baghel MS, Thakur MK. Social isolation mediated anxiety like behavior is associated with enhanced expression and regulation of BDNF in the female mouse brain. Phyisiol Behav. 2016;158:34-42. doi:10.1016/j.physbeh.2016.02.032

33. Huang S, Dong W, Jiao Z, et al. Prenatal dexamethasone exposure induced alterations in neurobehavior and hippocampal glutamatergic system balance in female rat offspring. Toxicol Sci. 2019;171:369-384. doi:10.1093/toxsci/kfz163

34. Viana Borges J, Souza de Freitas B, Antoniazzi V, et al. Social isolation and social support at adulthood affect epigenetic mechanisms, brain-derived neurotrophic factor levels and behavior of chronically stressed rats. Behav Brain Res. 2019;366:36-44. doi:10.1016/j.bbr.2019.03.025

35. Singh S, Siddiqui SA, Tripathy S, et al. Decreased level of histone acetylation in the infralimbic prefrontal cortex following immediate extinction may result in deficit of extinction memory. Brain Res Bull. 2018;140:355-364. doi:10.1016/j.brainresbull.2018.06.004

36. Wang DY, Kosowan J, Samsom J, et al. Inhibition of the G9a/GLP histone methyltransferase complex modulates anxiety-related behavior in mice. Acta Pharmacol Sin. 2018;39:866-874. doi:10.1038/ aps. 2017.190

37. Cittaro D, Lampis V, Luchetti A, et al. Histone modifications in a mouse model of early life adversities and panic disorder: role for Asic1 and neurodevelopmental genes. Sci Rep. 2016;6:25131. doi:10.1038/srep25131
38. Aten S, Page CE, Kalidindi A, et al. miR-132/212 is induced by stress and its dysregulation triggers anxiety-related behavior. Neuropharmacology. 2019;144:256-270. doi:10.1016/j.neurophar $\mathrm{m} .2018 .10 .020$

39. Cohen JL, Jackson NL, Ballestas ME, Webb WM, Lubin FD, Clinton SM. Amygdalar expression of the microRNA miR-101a and its target Ezh2 contribute to rodent anxiety-like behaviour. Eur J Neurosci. 2017;46:2241-2252. doi:10.1111/ejn.2017.46. issue-7

40. Liu Y, Liu D, Xu J, Jiang H, Pan F. Early adolescent stress-induced changes in prefrontal cortex miRNA-135a and hippocampal miRNA-16 in male rats. Dev Psychobiol. 2017;59:958-969. doi:10.1002/dev.v59.8

41. Hoban AE, Stilling RM, Moloney GM, et al. Microbial regulation of microRNA expression in the amygdala and prefrontal cortex. Microbiome. 2017;5:102. doi:10.1186/s40168-017-0321-3

42. Spadaro PA, Flavell CR, Widagdo J, et al. Long noncoding RNA-directed epigenetic regulation of gene expression is associated with anxiety-like behavior in mice. Biol Psychiatry. 2015;78:848-859. doi:10.1016/j.biopsych.2015.02.004

43. Lydiard RB. The role of GABA in anxiety disorders. $J$ Clin Psychiatry. 2003;64 Suppl:21-27.

44. Goddard AW, Mason GF, Almai A, et al. Reductions in occipital cortex GABA levels in panic disorder detected with ${ }^{1} \mathrm{H}$-magnetic resonance spectroscopy. Arch Gen Psychiatry. 2001;58:556-561. doi:10.1001/archpsyc.58.6.556

45. He Y, Ouyang J, Hu Z, et al. Intervention mechanism of repeated oral GABA administration on anxiety-like behaviors induced by emotional stress in rats. Psychiatry Res. 2019;271:649-657. doi:10.1016/j.psychres.2018.12.025

46. Alisch RS, Van Hulle C, Chopra P, et al. A multi-dimensional characterization of anxiety in monozygotic twin pairs reveals susceptibility loci in humans. Transl Psychiatry. 2017;7:1282. doi:10.1038/s41398-017-0047-9

47. Domschke K, Tidow N, Schrempf M, et al. Epigenetic signature of panic disorder: a role of glutamate decarboxylase 1(GAD1) DNA hypomethylation?. Prog Neuropsychopharmacol Biol Psychiatry. 2013;46:189-196. doi:10.1016/j.pnpbp.2013.07.014

48. Roberts S, Lester KJ, Hudson JL, et al. Serotonin transporter methylation and response to cognitive behaviour therapy in children with anxiety disorders. Transl Psychiatry. 2014;4:e444. doi:10.1038/tp.2014.83

49. Ziegler C, Richter J, Mahr M, et al. MAOA gene hypomethylation in panic disorder- reversibility of an epigenetic risk pattern by psychotherapy. Transl Psychiatry. 2016;6:e773. doi:10.1038/ tp.2016.41

50. Shimada-Sugimoto $M$, Otowa $T$, Miyagawa $T$, et al. Epigenome-wide association study of DNA methylation in panic disorder. Clin Epigenetics. 2017;9:6. doi:10.1186/s13148016-0307-1

51. Melas PA, Forsell Y. Hypomethylation of MAOA's first exon region in depression: a replication study. Psychiatry Res. 2015;226:389-391. doi:10.1016/j.psychres.2015.01.003

52. Ziegler C, Dannlowski U, Braüer D, et al. Oxytocin receptor gene methylation: converging multilevel evidence for a role in social anxiety. Neuropsychopharmacology. 2015;40:1528-1538. doi:1 $0.1038 / \mathrm{npp} .2015 .2$

53. Sanwald S, Gahr M, Widenhorn-Müller K, et al. Relation of promoter methylation of the oxytocin gene to stressful life events and depression severity. $J$ Mol Neurosci.2020; 70:201-211. doi:10.1007/s12031-019-01446-1

54. Murphy TM, O'Donovan A, Mullins N, O'Farrelly C, McCann A, Malone K. Anxiety is associated with higher levels of global DNA methylation and altered expression of epigenetic and interleukin-6 genes. Psychiatr Genet. 2015;25:71-78. doi:10.1097/YPG.0000000000000055 
55. Tyrka AR, Parade SH, Welch ES, et al. Methylation of the leukocyte glucocorticoid receptor gene promoter in adults: associations with early adversity and depressive, anxiety and substance-use disorders. Transl Psychiatry. 2016;6:e848. doi:10.1038/tp.2016.112

56. Prelog M, Hilligardt D, Schmidt CA, et al. Hypermethylation of FOXP3 promoter and premature aging of the immune system in female patients with panic disorder? PLoS One. 2016;11: e0157930. doi:10.1371/journal.pone.0157930

57. Iurato S, Carrillo-Roa T, Arloth J, et al. DNA methylation signatures in panic disorder. Transl Psychiatry. 2017;7:1287. doi:10.1038/ s41398-017-0026-1

58. Bortoluzzi A, Salum GA, da Rosa ED, Chagas VD, Castro MAA, Manfro GG. DNA methylation in adolescents with anxiety disorder: a longitudinal study. Sci Rep. 2018;8:13800.

59. Ciuculete DM, Boström AE, Tuunainen A-K, et al. Changes in methylation within the STK32B promoter are associated with an increased risk for generalized anxiety disorder in adolescents. $J$ Psychiatr Res. 2018;102:44-51. doi:10.1016/j.jpsychires.2018.03.008

60. Kang H-J, Kim K-O, Kim J-W, et al. A longitudinal study of the associations of BDNF genotype and methylation with poststroke anxiety. Int J Geriatr Psychiatry. 2019;34:1706-1715. doi:10.1002/ gps.v34.11

61. Palma-Gudiel H, Cordova-Palomera A, Tornador C, et al. Increased methylation at an unexplored glucocorticoid responsive element within exon $1_{\mathrm{D}}$ of $\mathrm{NR} 3 \mathrm{C} 1$ gene is related to anxious-depressive disorders and decreased hippocampal connectivity. Eur Neuropsychopharmacol. 2018;28:579-588. doi:10.1016/j.euroneuro. 2018.03.015

62. Bosmans G, Young JF, Hankin BL. NR3C1 methylation as a moderator of the effects of maternal support and stress on insecure attachment development. Dev Psychol. 2018;54:29-38. doi:10.1037/dev0000422

63. Roberts S, Keers R, Breen G, et al. DNA methylation of FKPB5 and response to exposure-based psychological therapy. Am J Med Genet B. 2019;180:150-158. doi:10.1002/ajmg.b.32650

64. Chagnon YC, Potvin O, Hudon C, Préville M. DNA methylation and single nucleotide variants in the brain-derived neurotrophic factor (BDNF) and oxytocin receptor (OXTR) genes are associated with anxiety/depression in older women. Front Genet. 2015;30(6):230.

65. Hommers LG, Richter J, Yang Y, et al. A functional genetic variation of SLC6A2 repressor has-miR-579-3p upregulates sympathetic noradrenergic processes of fear and anxiety. Transl Psychiatry. 2018;8:226. doi:10.1038/s41398-018-0278-4

66. Chen SD, Sun XY, Niu W, et al. Correlation between the level of microRNA expression in peripheral blood mononuclear cells and symptomatology in patients with generalized anxiety disorder. Compr Psychiatry. 2016;69:216-224. doi:10.1016/j.comppsych. 2016.05.006

67. Dickson DA, Paulus JK, Mensah V, et al. Reduced levels of miRNAs 449 and 34 in sperm of mice and men exposed to early life stress. Transl Psychiatry. 2018;8:101. doi:10.1038/ s41398-018-0146-2

68. Jacobsen DP, Eriksen MB, Rajalingam D, et al. Exposure to workplace bullying, microRNAs and pain; Evidence of a moderating effect of miR-30c rs928508 and miR-223 rs3848900. Stress. 2020;23:77-86. doi:10.1080/10253890.2019.1642320

69. Hettema JM, Otowa T. Genetics of anxiety disorders. In: Sadock BJ, Sadock VA, Ruiz P, editors. Kaplan \& Sadock's Comprehensive Textbook of Psychiatry. Philadelphia, PA: Wolters Kluwer; 2017:1737-1741.

70. Bartlett AA, Lapp HE, Hunter RG. Epigenetic mechanisms of the glucocorticoid receptor. Trends Endocrinol Metab. 2019;30: 807-818. doi:10.1016/j.tem.2019.07.003

71. Champagne FA. Beyond the maternal epigenetic legacy. Nat Neurosci. 2018;21:773-774. doi:10.1038/s41593-018-0157-6
72. Lee JB, Wei J, Liu W, Cheng J, Feng J, Yan Z. Histone deacetylase 6 gates the synaptic action of acute stress in prefrontal cortex. $J$ Physiol. 2012;590:1535-1546. doi:10.1113/jphysiol.2011.224 907

73. Espallergues J, Teegarden SL, Veerakumar A, et al. HDAC6 regulates glucocorticoid receptor signaling in serotonin pathways with critical impact on stress resilience. J Neurosci. 2012;32:4400-4416. doi:10.1523/JNEUROSCI.5634-11.2012

74. Roberts S, Keers R, Lester KJ, et al. HPA axis related genes and response to psychological therapies: genetics and epigenetics. Depress Anxiety. 2015;32:861-870. doi:10.1002/da.22430

75. Hempstead BL. Brain-derived neurotrophic factor: three ligands, many actions. Trans Am Clin Climatol Assoc. 2015; 126:9-19.

76. Suliman S, Hemmings SM, Seedat S. Brain-derived neurotrophic factor (BDNF) protein levels in anxiety disorders: systematic review and meta-regression analysis. Front Integr Neurosci. 2013;7:55. doi:10.3389/fnint.2013.00055

77. Varela MA, Roberts TC, Wood MJA. Epigenetics and ncRNAs in brain function and disease: mechanisms and prospects for therapy. Neurotherapeutics. 2013;10:621-631. doi:10.1007/s13311-0130212-7

78. Murphy CP, Singewald N. Role of microRNAs in anxiety and anxiety-related disorders. Curr Top Behav Neurosci. 2019; 42:185-220.

79. Hadjiargyrao M, Delihas N. The intertwining of transposable elements and non-coding RNAs. Int J Mol Sci. 2013;14:13307-13328. doi:10.3390/ijms140713307

80. Guffanti G, Bartlett A, DeCrescenzo P, Macciardi F, Hunter R Transposable elements. Curr Top Behav Neurosci. 2019;42: 221-246.

81. Hunter RG, McEwen BS. Stress and anxiety across the lifespan: structural plasticity and epigenetic regulation. Epigenomics. 2013;5:177-194. doi:10.2217/epi.13.8

82. Whittle N, Schmuckermair C, Gunduz Cinar O, et al. Deep brain stimulation, histone deacetylase inhibitors and glutamatergic drugs rescue resistance to fear extinction in a genetic mouse model. Neuropharmacology. 2013;64:414-423. doi:10.1016/j. neuropharm.2012.06.001

83. Sakharkar AJ, Zhang H, Tang L, et al. Effects of histone deacetylase inhibitors on amygdaloid histone acetylation and neuropeptide Y expression: a role in anxiety-like and alcohol-drinking behaviours. Int J Neuropsychopharmacol. 2014;17:1207-1220. doi:10.1017/S1461145714000054

84. You C, Zhang H, Sakharkar AJ, Teppen T, Pandey SC. Reversal of deficits in dendritic spines, BDNF and Arc expression in the amygdala during alcohol dependence by HDAC inhibitor treatment. Int J Neuropsychopharmacol. 2014;17:313-322. doi:10.1017/S1461 145713001144

85. Tran L, Schulkin J, Ligon CO, Greenwood-van Meerveld B Epigenetic modulation of chronic anxiety and pain by histone deacetylation. Mol Psychiatry. 2015;20:1219-1231. doi:10.1038/ mp.2014.122

86. Moloney RD, Stilling RM, Dinan TG, Cryan JF. Early-life stress-induced visceral hypersensitivity and anxiety behavior is reversed by histone deacetylase inhibition. Neurogastroenterol Motil. 2015;27:1831-1836. doi:10.1111/nmo.12675

87. Sah A, Sotnikov S, Kharitonova M, et al. Epigenetic mechanisms within the cingulate cortex regulate innate anxiety-like behavior. Int J Neuropsychopharmacol. 2019;22:317-328. doi:10.1093/ijnp/ pyz004

88. Montagud-Romero S, Cantacorps L, Valverde O. Histone deacetylases inhibitor trichostatin A reverses anxiety-like symptoms and memory impairments induced by maternal binge alcohol drinking in mice. J Psychopharmacol. 2019;33:1573-1587. doi:10.1177/0269 881119857208 
89. Hayase T. Putative epigenetic involvement of the endocannabinoid system in anxiety-and depression-related behaviors caused by nicotine as a stressor. PLoS One. 2016;11:e0158950. doi:10.1371/journal.pone.0158950

90. Kv A, Madhana RM, Js IC, Lahkar M, Sinha S, Naidu VGM. Antidepressant activity of vorinostat is associated with amelioration of oxidative stress and inflammation in a corticosterone-induced chronic stress model in mice. Behav Brain Res. 2018;344:73-84. doi:10.1016/j.bbr.2018.02.009

91. Karnib N, El-Ghandour R, El Hayek L, et al. Lactate is an antidepressant that mediates resilience to stress by modulating the hippocampal levels and activity of histone deacetylases. Neuropsychopharmacology. 2019;44:1152-1162. doi:10.1038/ s41386-019-0313-z

92. Park J, Terranova-Barberio M, Zhong AY, Thomas S, Munster PN. Clinical applications of histone deacetylase inhibitors. In: Tollefsbol TO, editor. Handbook of Epigenetics: The New Molecular and Medical Genetics. Cambridge, MA: Elsevier; 2017:605-621.

93. Primeau F, Fontaine R, Beauclair L. Valproic acid and panic disorder. Can J Psychiatry. 1990;35:248-250. doi:10.1177/ 070674379003500309

94. Keck PE, Taylor VE, Tugrul KC, McElroy SL, Bennett JA. Valproate treatment of panic disorder and lactate-induced panic attacks. Biol Psychiatry. 1993;33:542-546. doi:10.1016/00063223(93)90010-B

95. Woodman CL, Noyes R. Panic disorder: treatment with valproate. J Clin Psychiatry. 1994;55:134-136.

96. Kinrys G, Pollack MH, Simon NM, Worthington JJ, Nardi AE, Versiani M. Valproic acid for the treatment of social anxiety disorder. Int Clin Psychopharmacol. 2003;18:169-172. doi:10.1097/01.yic.0000064261.66765.9f

97. Aliyev NA, Aliyev ZN. Valproate (depakine-chrono) in the acute treatment of outpatients with generalized anxiety disorder without psychiatric comorbidity: randomized, double-blind placebo-controlled study. Eur Psychiatry. 2008;23:109-114. doi:10.1016/j.eurpsy.2007.08.001
98. Bach DR, Korn CW, Vunder J, Bantel A. Effect of valproate and pregabalin on human anxiety-like behaviour in a randomized controlled trial. Transl Psychiatry. 2018;8:157. doi:10.1038/ s41398-018-0206-7

99. Scott KA, Hoban AE, Clarke G, Moloney GM, Dinan TG, Cryan JF. Thinking small: towards microRNA-based therapeutics for anxiety disorders. Expert Opin Investig Drugs. 2015;24:529-542. doi:10.1517/13543784.2014.997873

100. Roy-Byrne P. Treatment-refractory anxiety; Definition, risk factors, and treatment challenges. Dialogues Clin Neurosci. 2015;17:191-206.

101. Seto E, Yoshida M. Erasers of histone acetylation: the histone deacetylase enzymes. In: Allis CD, Caparros M-L, Jenuwein T, Reinberg D, Lachner M, editors. Epigenetics. Cold Spring Harbor, NY: Cold Spring Harbor Laboratory Press; 2015: 143-168.

102. Choudhary C, Kumar C, Gnad F, et al. Lysine acetylation targets protein complexes and co-regulates major cellular functions. Science. 2009;325:834-840. doi:10.1126/science.1175371

103. Dokmanovic M, Marks PA. Prospects: histone deacetylase inhibitors. J Cell Biochem. 2005;96:293-304. doi:10.1002/ (ISSN)1097-4644

104. Li W, Sun Z. Mechanism of action for HDAC inhibitors insights from omics approaches. Int J Mol Sci. 2019;20(7):1616. doi:10.3390/ijms20071616

105. Guidotti A, Grayson DR. DNA methylation and demethylation as targets for antipsychotic therapy. Dialogues Clin Neurosci. 2014;16:419-429.

106. Wei Y, Melas PA, Wegener G, Mathé AA, Lavebratt C. Antidepressant-like effect of sodium butyrate is associated with an increase in TET1 and in 5-hydroxymethylation levels in the BDNF gene. Int J Neuropsychopharmacol. 2014;18(2).

107. Peedicayil J, Kumar A. Epigenetic drugs for mood disorders. Prog Mol Biol Transl Sci. 2018;157:151-174.

108. Whittle N, Singewald N. HDAC inhibitors as cognitive enhancers in fear, anxiety and trauma therapy: where do we stand?. Biochem Soc Trans. 2014;42:569-581. doi:10.1042/BST20130233

\section{Publish your work in this journal}

Neuropsychiatric Disease and Treatment is an international, peerreviewed journal of clinical therapeutics and pharmacology focusing on concise rapid reporting of clinical or pre-clinical studies on a range of neuropsychiatric and neurological disorders. This journal is indexed on PubMed Central, the 'PsycINFO' database and CAS, and is the official journal of The International Neuropsychiatric Association (INA). The manuscript management system is completely online and includes a very quick and fair peer-review system, which is all easy to use. Visit http://www.dovepress.com/testimonials.php to read real quotes from published authors. 